\title{
REAL AGE-ADJUSTED LIFE EXPECTANCY
}

\author{
Duncan Palmer \# \\ University of Stellenbosch \\ duncs@sun.ac.za
}

\author{
Niel Krige+ \\ University of Stellenbosch \\ jdkrige@sun.ac.za
}

June 2012

\begin{abstract}
This study summarises the development of a model to determine an individual's adjusted life expectancy based on his Real Age. The model incorporates aspects such as gender, residing province, income, HIV status, ethnic background, weight, exercise, family illness history, stress, substance abuse and diet. Predicting life expectancy is vital in retirement planning for two reasons: 1) given the diverse nature of South Africa, the national average life expectancy cannot be applied to everyone; and 2) retirement duration forms a vital part in the retirement planning process. Retirees can make more informed financial investment decisions based on their Real Age, thus increasing the probability of having sufficient funds during retirement. Three representative examples of South African Real Age-adjusted life expectancies were simulated, predicting life expectancies of 67, 72 and 87 years, notably different from the 50 year average South African life expectancy.
\end{abstract}

Keywords

life expectancy, pension planning, real age, survival probability

\#Duncan Palmer is a master's student at the University of Stellenbosch Business School, Stellenbosch, South Africa.

+Prof Niel Krige is professor at the University of Stellenbosch Business School, Stellenbosch, South Africa. 


\section{INTRODUCTION}

National average life expectancy in South Africa (SA) is short, but due to the wide diversity of socio-economic groupings in the country, a longevity measure requires flexibility and has to be tailored to each individual. All the different factors affecting life expectancy must be accounted for. In this study a person's lifestyle and health are used to assess his/her life expectancy using his/her 'real' age.

Real Age is a relatively new concept, believed to have first been introduced by Dr Michael Roizen in his book Real Age: Are you as young as you can be? (Thompson, 2008). The Real Age principle is that lifestyle choices affect one's health and one could thus be older or younger than one's calendar age. Millions of people in the United States (US) have completed a Real Age questionnaire online (based on US circumstances) with the primary goal of making people aware of just what they are doing to their body and its long-term influence. One's Real Age is therefore a very important input in retirement planning. In this study the South African national life expectancy is taken as the base and then adjusted with Real Age parameters.

Life expectancy varies widely according to gender, the province in which one lives, ethnic background, HIV status and a number of other factors. Financial well-being also has a part to play because of access to better health care and nutrition. A brief overview of the SA economy is given to highlight this discrepancy. The foundations of the Adjusted Life Expectancy (ALE) Model are gender and which province one lives in. Based on these factors, years are either added or subtracted according to other inputs. The term used to refer to the calculated bespoke life expectancy is the adjusted life expectancy, or the ALE Model.

The ALE Model can be used in isolation, but was in fact developed with a specific end goal in mind. It formed the basis for a further model, the Pensions Model, in which one looks at the correlation between withdrawal rate and risk tolerance in order to obtain a financial survival probability, if the retirement duration is known. The development and outcome of the Pensions Model will be published in a successive article (see The Financial Survival Probability of Living Annuitants) in this issue of the journal.

The remainder of this paper is organised as follows. Section 2 reviews the SA retirement system, varying life expectancy in SA and the importance of the Real Age concept in retirement planning. Section 3 discusses the development of the ALE Model. Section 4 reports the results and Section 5 discusses conclusions.

\section{BACKGROUND}

In this section the current South African pension structures will be discussed. This will be followed by a discussion of the variations in South African life expectancy over time and between provinces. Finally, the Real Age concept will be introduced.

\subsection{Pension structures}

There are three structures forming the foundation of the retirement system in SA (National Treasury, 2004). 
The first structure is that of old-age state pensions, which focuses on redistribution to prevent poverty among the elderly. This is investigated further in section 2.1.1. Retirees in this group will not be able to utilise the ALE and Pensions Models, as they are entirely dependent on the oldage state pension, with hardly any discretionary savings in most cases.

The second structure is that of occupational retirement funds and privately managed retirement funds (typically individuals in the formal sector). The Government Employees Pension Fund (GEPF) is an example where the members must be government employees and are required to make fixed contributions.

The last structure is that of voluntary savings, in which individuals choose how income is allocated over their lifetime. The focus of this study will be on individuals utilising this structure.

\subsubsection{Old-age state pensions}

Old-age state pensions are in place to help alleviate poverty amongst the elderly, but are major targets for white-collar crime and corruption. Sub-Saharan Africa has been targeted as an area requiring reform to remove corruption and inefficiencies (Barbone \& Sanchez, 1999). Despite today's technology and widespread banking facilities available, still the most common form of pension pay-out is that of queuing at a specified point and collecting cash. The problems associated with these points are endless: queue time, lack of facilities, seating and, most importantly, security. The pension has to be collected in person, so people leave hospitals to collect pensions, and death in queues is not unheard of. When they arrive at the front of the queue, pensioners may be subject to abuse, refusal or cheating from staff members (Mothers and Fathers, 2001).

If not all elderly people were to receive a state old-age pension, the social impact would be massive. A study by Ardington and Lund (1994) revealed that in KwaZulu-Natal pensioners are seen as financial assets and not liabilities in that they contribute more than half the household income for one-third of the rural residences. Research has shown that these families enjoy measurably better nutrition and are thus in better health. Statistics South Africa (2007:42) showed that there were almost 2.4 million people receiving state pensions in 2007, see TABLE 1 .

TABLE 1: Number Of Males And Females Receiving State Old-Age Pensions

\begin{tabular}{lrrrr}
\hline \multicolumn{1}{c}{ Type of social grant } & \multicolumn{1}{c}{ Male } & Female & \multicolumn{1}{c}{ TOTAL } \\
\hline Old age pension & & & & \\
Disability grant & 628998 & 1738322 & 2367320 & 21.2 \\
Child support grant & 606242 & 580251 & 1186493 & 10.6 \\
Care dependence grant & 3576534 & 3616392 & 7192926 & 64.5 \\
Foster care grant & 95992 & 86373 & 182365 & 1.6 \\
Grant in aid & 8981 & 14204 & 23185 & 0.20 \\
Social relief & 39162 & 63160 & 102322 & 0.9 \\
Multiple social grants & 18112 & 21533 & 39645 & 0.4 \\
TOTAL & 24936 & 31211 & 56147 & 0.5 \\
\hline
\end{tabular}

Source: Statistics South Africa (2007:42) 


\subsubsection{Private sector}

There is legislation in place, first codified in 1956, governing the way pensions are managed. The Act has been amended many times since inception, adding features such as member-elected trustees and surplus apportionment. The Act has thus been kept up to date and is reviewed on a regular basis by various committees. In the 1970s, defined benefit funds were the most common type of fund and were managed by employers. These types of funds favoured retirement and death, not resignation, so employers used them as a means to retain employees. The 1980s and 1990s saw a dramatic transfer from defined benefit to defined contribution funds, also resulting in better resignation benefits. Employers also preferred defined contribution funds, as, among other benefits, these transferred the investment risk and expenses to employees. Today, defined contribution funds are the most popular fund type (National Treasury, 2004).

South Africa does not have a state pension scheme to which individuals could contribute if they were privately employed. Individuals thus either contribute to a company-based pension fund or to a retirement annuity fund administered by a financial institution. Old Mutual, for example, offers one of the oldest and largest retirement annuities (RAs), namely the South African Retirement Annuity Fund (SARAF). This RA is not attached to any employer, membership is voluntary, and there are tax benefits (South African Retirement Annuity Fund, 2011). These traits describe not only SARAF, but most RAs in general. It is in this sector where individuals can determine their monthly contributions, and where adapting the monthly contributions for one's Real Age-adjusted life expectancy would be most beneficial.

\subsection{South African life expectancy}

It would not be sound to base a retirement portfolio on, say, US data and life expectancies, because SA is a developing country with a myriad of diseases and life risks. Firstly, life expectancy is not fixed: it varies over time with healthcare, economic conditions and prevalent diseases. FIGURE 1 shows that SA's life expectancy is just over 50 years, while that of the rest of the world is an average of almost 70 years. Also note for South Africa the drastic decrease in age of almost ten years since 1995, predominately due to the impact of Aids (Mail and Guardian, 2009).

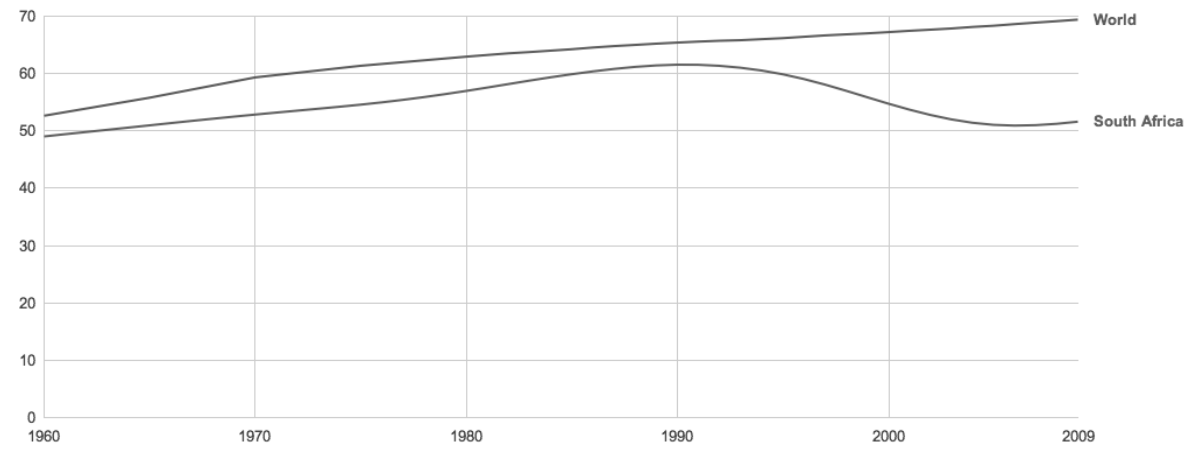

FIGURE 1: Life expectancy of SA compared to the rest of the world

Source: World Bank (2011) 
The 50-year age figure is based on South Africa as a whole, which if used as part of one's Real Age determination, would also be an incorrect assumption. South Africa has one of the highest Gini coefficients (the difference between rich and poor) in the world. So there are candidates likely to live to first-world life expectancies of $80+$ years, because of access to first-rate health care facilities, food and shelter (the higher living standards measures (LSMs)). On the opposite end of the scale are the people in the lower LSMs and who are truly third world. The life expectancy can further be broken down per province. FIGURE 2 and FIGURE 3 show the life expectancy for males and females depending on which province they live in. It is evident from these figures that life expectancy can vary by more than 10 years between provinces (Statistics South Africa, 2011a).

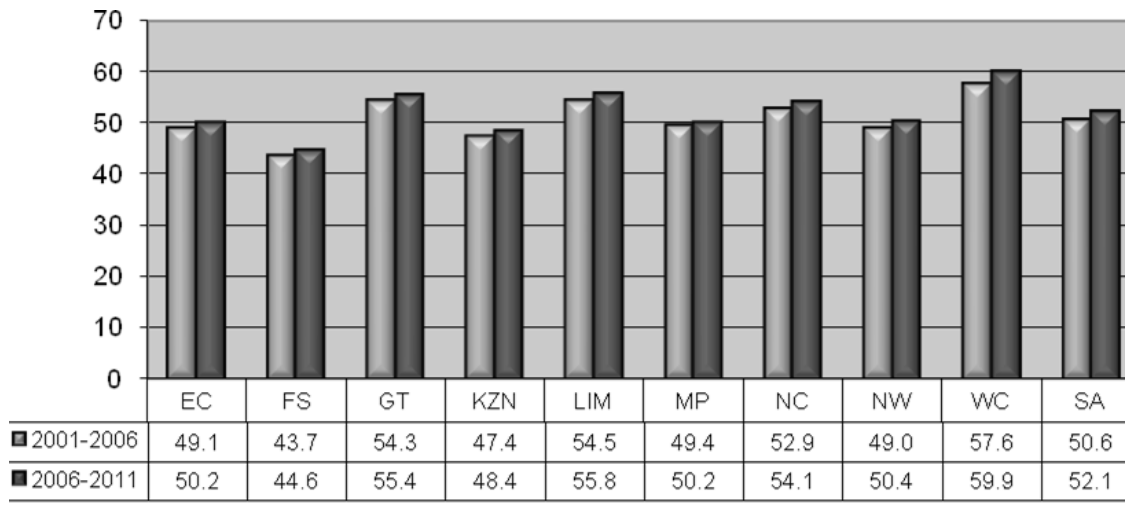

FIGURE 2: Life expectancy per province (male)

Source: Statistics South Africa (2011a)

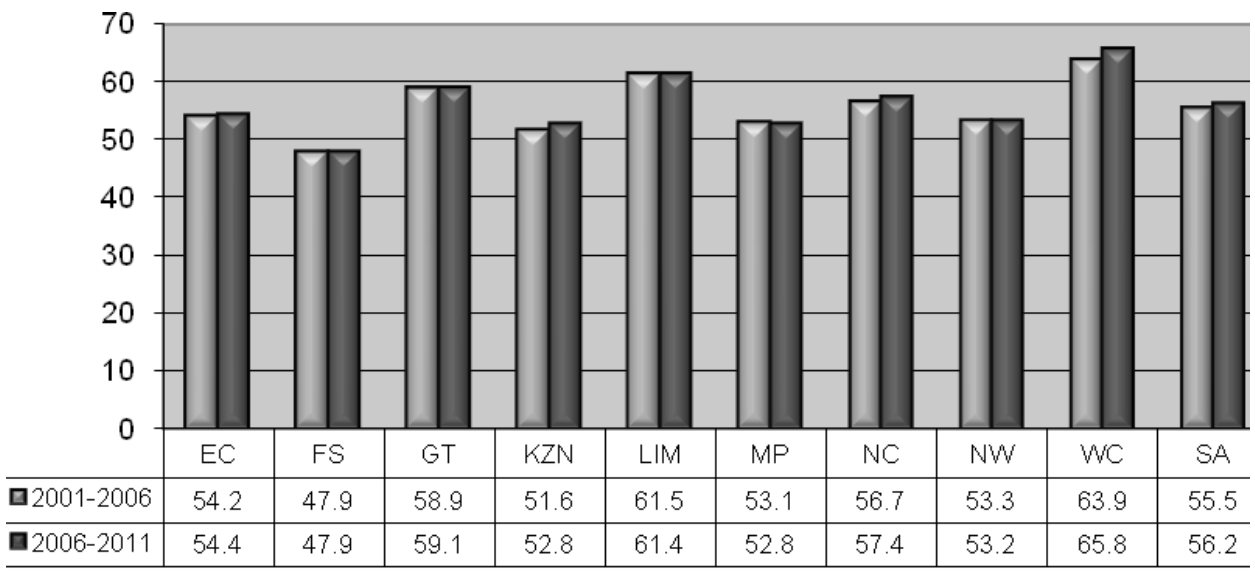

FIGURE 3: Life expectancy per province (female)

Source: Statistics South Africa (2011a) 


\subsection{Real age}

The idea of Real Age, or that somebody can be physically younger or older than his or her calendar age, was possibly first introduced by Dr Michael Roizen in his book Real Age: Are you as young as you can be? (Thompson, 2008). The Real Age concept was developed in recognition of the fact that one's life expectancy is influenced by factors such as lifestyle and family history.

All the data pertaining to Real Age in the US was condensed into an online tool which is explained on the website www.realage.com. Since its inception in 1998, more than 27 million people have taken the online test. Many more sites have come online over the years that also calculate one's real age:

- www.healthreviser.com/content/biological-age-test

- http://www.helloquizzy.com/tests/the-what-is-your-real-age-test/

- www.oprah.com/health/Quiz-What-is-Your-Real-Age

- www.mytrueage.com

- www.growyouthful.com

Real Age is predominately about preventative gerontology. Most people would agree that slowing down the ageing process through a healthy lifestyle is better than dying prematurely. Part of this prevention process is becoming aware of the impact of daily decisions on health and then making the needed adjustments.

So, if Real Age has such huge implications on an individual's life, then it must definitely influence the way one thinks about planning for retirement. It can therefore play a key role in forecasting one's life expectancy and thus preventing money death. The term "money death" has recently been developed in the US and refers to the risk that a pensioner may run out of money in retirement.

\section{ADJUSTED LIFE EXPECTANCY MODEL}

A simulator was developed for South Africa to determine a person's Real Age-adjusted life expectancy. Life expectancy is always changing (see FIGURE 1), but for simplicity's sake the model will be static and based on 2011 figures. It must be emphasised that the output of the model is an adjusted life expectancy which is independent of the existing calendar age of the participant.

The base of the simulator is the life expectancy according to province and gender. Years are then added or subtracted according to the inputs. For example, a male living in the Western Cape has a life expectancy of 59.9 years (Statistics South Africa, 2011a). The other factors which have been taken into account in developing the ALE model are presented in the flow chart in FIGURE 4. 


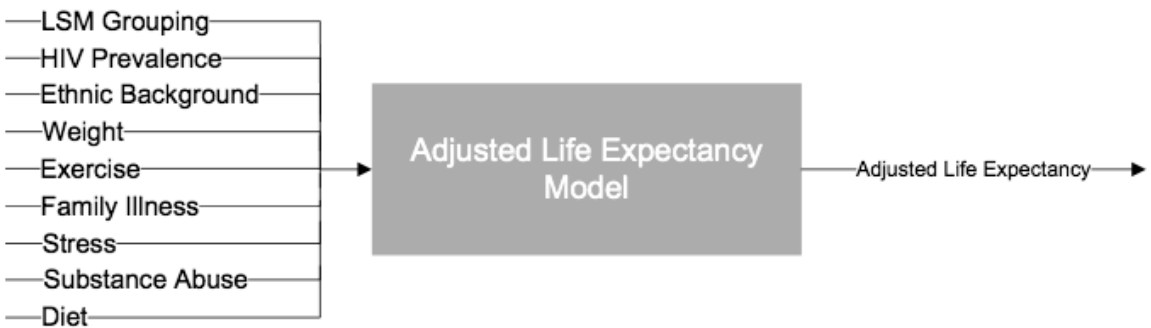

FIGURE 4: Flow chart showing the ale inputs and outputs

\section{Source: Created by authors}

\subsection{Input: Living standards measure grouping}

Given the Gini coefficient, there are sectors in SA that will live to the life expectancy of developed countries, in this case up to twenty years longer than the national average. If a person is planning to retire and statistically he/she is likely to live more than half his/her life again, the chance of money death becomes significant. The LSM grouping is thus added as the second input to the simulator. LSM information and detailed age statistics are compiled in the South African Audience Research Foundation's AMPS ${ }^{\circledast}$ database (Tracey, 2012). Life expectancy for each LSM was determined based on this information, with the exclusion of LSM 1 because of low data integrity as cautioned in the AMPS ${ }^{\oplus}$ database. The difference in life expectancy between the high and low LSM group is 20 years, which will form the basis of the LSM input.

\subsection{Input: HIV prevalence}

HIV/Aids is epidemic in SA, and it is unlikely that it will be eradicated in the near future. It is thus an important input in the simulator, because according to the National Health Service in the United Kingdom a person could still live up to sixty-six years old if treated correctly (National Health Service, 2011). The National Health Service study states that HIV infection causes life expectancy to be twenty years shorter than the normal life expectancy in the United Kingdom, so if a person has HIV/Aids, his/her life expectancy will decrease by about $25 \%$. In this study HIV prevalence is based per province (see FIGURE 5), assuming the HIV status is not known. If a person is known to be HIV positive, then it is assumed that this person's life expectancy decreases by $25 \%$, similar to the UK experience referred to above. If it is not known, there is still a risk of having HIV, as so few people are tested. In this case, the decrease in life expectancy is calculated by taking the provincial prevalence (as years, not percentage) multiplied by $25 \%$. If tested with no positive results, there is no impact on life expectancy.

\subsection{Input: Ethnic background}

Racial profiling, though banned for political purposes, still has an important role to play in determining life expectancy in SA. A study conducted by Cutler, Fryer and Glaeser in 2005 showed that life expectancy among black people was six years less than among white people. 


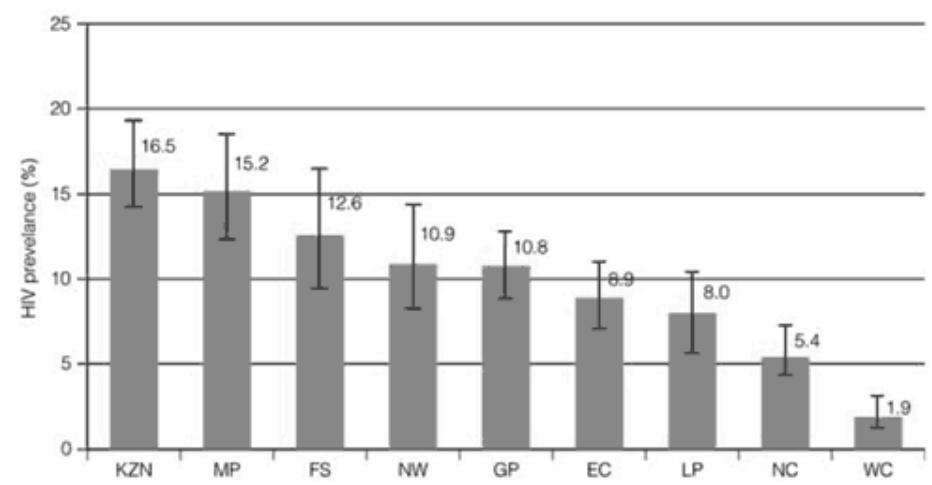

FIGURE 5: HIV prevalence per province

\section{Source: Human Sciences Research Council (2005)}

The assumption in the model is that the life expectancy of white people will increase by three years. If Coloured and Indian, no adjustment is made, whereas the life expectancy of black people is decreased by three years.

\subsection{Input: Weight}

The World Health Organisation (2011) states that obesity is the fifth-largest cause of death worldwide. It is also one of the first questions asked in any Real Age survey. Obesity is becoming a problem in South Africa despite it still being a developing country. $59 \%$ of women and $29 \%$ of men are considered to be obese (Van der Merwe \& Pepper, 2005). A cohort US-based population study found that the life expectancy of 40 -year old non-smoking males who were twenty kilograms overweight was reduced by eight years compared with their counterparts with optimal body mass (Peeters, Barendregt, Willekens, Mackenbach, Al Mamun \& Bonneux, 2003). Theoretically, the body mass index should be calculated for each person, but for simplicity's sake, kilograms overweight will be used. Based on the Peeters et al. (2003) study, the relationship between kilograms to years' decrease in life expectancy is assumed to be 0.4 . So if a person is ten kilos overweight, he/she can expect to live for four years less.

\subsection{Input: Exercise}

A recent study from Wen, Wai, Tsai, Yang, Cheng, Lee, Chan, Tsao, Tsai and Wu (2011) concluded that exercising thirty minutes per day increases life expectancy by three to four years. This is, however, not indefinitely continuous - exercising for ten hours a day will not increase life expectancy by sixty to eighty years. Thus a cap is set on five years in the model if a person exercises for an hour or more per day.

\subsection{Input: Family history of illness}

There are many hereditary diseases, such as Huntington's disease, Marfan syndrome and cancer, and a person is at higher risk if the gene is in the family. It's near impossible to determine the relevance for each person, thus a notional value will be applied in the simulator. According to the Bankrate Life Expectancy Calculator (2012), life expectancy decreases by three years if both 
parents die of illnesses before the age of 60 . This is the extreme case, so for the purpose of this study family history is broken down into three categories: high prevalence, prevalent and not prevalent. In each case three years, one and a half years and nil years are subtracted from the life expectancy, respectively.

\subsection{Input: Stress}

Life has definitely become more stressful, faster paced and less forgiving than it was fifty years ago. Stress can have negative effects on one's health and potentially leads to depression and obesity/anorexia, thus diminishing life expectancy. Foster, Chua and Ungar (2012) indicated in their life expectancy calculator that a single stress factor, such as divorce or financial trouble, decreases life expectancy by up to one year. It is possible to have multiple stress factors at one time, so two years is the maximum possible decrease in life expectancy.

\subsection{Input: Substance abuse}

Smoking, drugs and (prescription) substance usage without moderation cause long-term damage. Smoking was shown to decrease life expectancy by two to four years (Ferrucci, Izmirlian, Leveille, Phillips, Corti, Brock \& Guralink 1999). The model reduces life expectancy by four years for smokers and by two years for persons who smoked at any time during their lives. Drugs and substance abuse are far more serious than smoking. This will, however, be hard for the portfolio planner to determine, because this information is not readily discussed. It will therefore not be taken into account in this study.

\subsection{Input: Diet}

The final input into the simulator is diet. This input relies on an honest answer to: are healthy foods being eaten and is a balanced diet being followed? Fast foods and high starch meals do not fall into a healthy diet category. A balanced meal consists of meat (in moderation), salads or vegetables and at least three meals per day must be consumed. Foster et al. (2012) determined that two years could be gained in life expectancy if a diverse, healthy diet is maintained. For the purpose of this input, two years will be added for healthy eating, no change for an average diet, and, finally, two years subtracted for an unhealthy diet.

\subsection{Interdependence between factors}

The inputs described above were determined assuming no interdependence between them. For example, stress and exercise each affected the life expectancy separately. However, in reality they are linked, as most people who exercise are in better control of their stress, for example, so some of these inputs cannot be considered discrete inputs. The following factors are assumed to be discrete:

- LSM grouping

- HIV status

- Ethnic background

- Family history of illness

The remaining factors - weight, diet, substance abuse, stress and exercise - are assumed to have some form of correlation. It is not possible to determine the relationship between all the 
factors together, so they will be analysed in pairs. The correlation between substance abuse (specifically smoking) and obesity was determined in a study by Peeters et al. (2003). Obese female smokers reduced their life expectancy by 13.3 years, while obese male smokers did so by 13.7 years. Their model predicted that a twenty kilograms overweight smoker will have a decreased life expectancy of twelve years and made no distinction between male and female. Their study revealed that the life expectancy decrease was compounded when factors were interdependent. The adjustment factor in the ALE Model includes a term where an obese female smoker's life expectancy is decreased a further $11 \%$, while for obese male smokers this is $12.4 \%$.

Hughes (1984) conducted a study in which published literature was reviewed to determine whether there are any psychological benefits of regular aerobic exercise. These included mood control, personality and cognition. This study was investigated because the possible interdependence between exercise and stress relief needed to be established. The results concluded that no psychological benefit was to be gained from exercising. Hughes, Casal and Leon (1986) conducted a study on a trial group of men for conducting solitary exercise to determine psychological improvement. The study revealed that exercise did not improve tension, anger, depression or a host of other conditions. Improvement was thus attributed to other aspects surrounding exercise, such as the social aspect or the training effect. A more recent study by DiLorenzo, Bargman, Stucky-Ropp, Brassington, Frensch and LaFontaine (1999) concluded that there were significant gains to be had in terms of stress relief and emotional well-being resulting from regular exercise. The study did not specify whether the exercise was done alone or socially. Given the complicating nature of these results, it will be assumed for this model that exercise is done socially and that there are benefits. The result indicates that if a person is stressed the benefits of exercise are not fully obtainable. The difference between the two factors will be used as the interdependence adjustment factor. The outcome of this is that if a person is stressed, the impact of exercise is lessened. The adjustment is a decrease in life expectancy of a maximum of two years.

Diet is the most challenging factor to integrate into the model, because it has a wide influence, affecting weight, exercise results, and, potentially, emotional well-being. The interdependence of diet and weight will thus be assumed to halve the impact of a healthy diet; this is because the benefits of healthy eating have already been factored in. Exercise and diet should also be related. If one is exercising and not eating correctly, one's life expectancy is expected to decrease. Effects of an unhealthy diet on life expectancy will thus be halved for the individual who is exercising regularly.

The interdependence between HIV and province was considered, but it is ignored. KwaZuluNatal, for example, has the highest HIV prevalence, but only the second-lowest life expectancy. This illustrates that there are other province-specific factors, such as health care, violence and income level, that impact life expectancy. Examining the other provinces, it also appears as though there is no direct correlation between life expectancy and HIV prevalence in the province. 


\section{RESULTS}

Three fictitious representative persons' results were simulated in the Real Age-adjusted life expectancy model as a test. The individuals are described below with their resulting life expectancy given. In each case a graphical interface of the Real Age-adjusted life expectancy model is presented.

\subsection{Person_X}

The first individual, named Person_X, is a white male living in the Western Cape. Degreeeducated, this person resides in the LSM 10 group, and has private medical aid and a large portion of disposable income. No Aids test has been taken. Person_X is health-conscious, exercises regularly, eats healthily and is carrying no extra weight. There is a small history of illness in the family, prostate cancer and minor heart disease. He is no part of the corporate world, so stress is kept to a minimum, and he doesn't smoke. FIGURE 6 displays the model simulation for Person_X.

- THE REAL AGE-ADJUSTED LIFE EXPECTANCY FOR PERSON_X IS 87 YEARS.

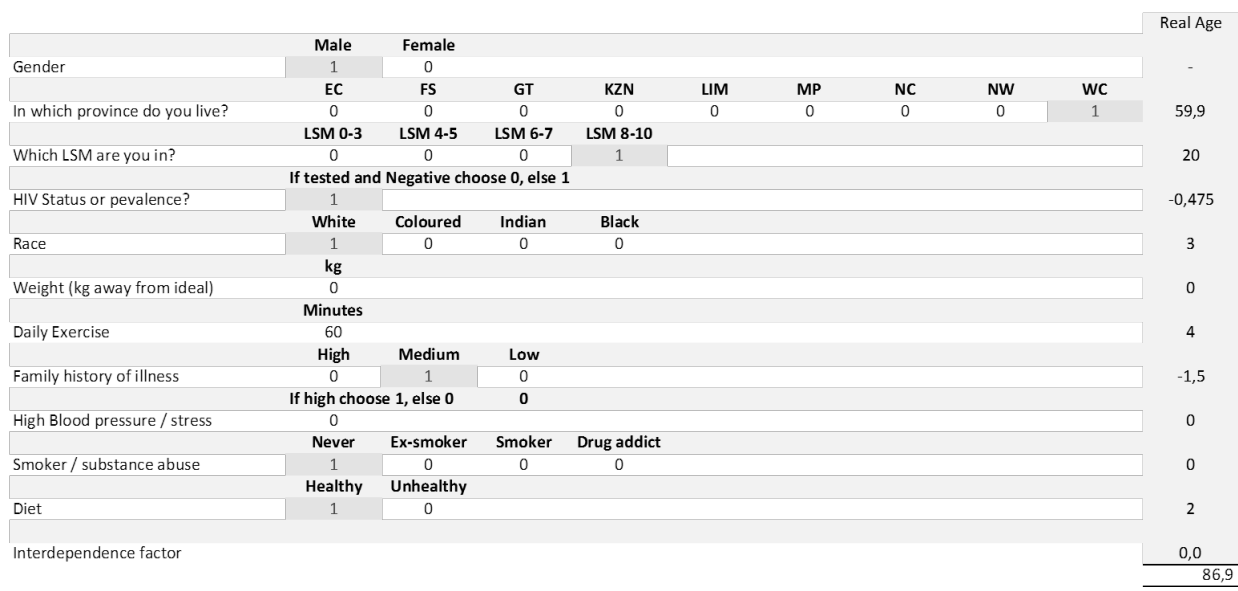

\section{FIGURE 6: Graphical interface showing simulation of Person_X}

\section{Source: Created by authors}

\subsection{Person_y}

Person_y is a black female living in Limpopo. Also degree-educated and a working professional, she provides the sole income to the house. Given the lower disposable income, they reside in LSM 7. She has been HIV tested (result: negative) and is in good physical shape due to $30 \mathrm{~min}$ per day exercise and a healthy diet. Similar to Person_X, she does not smoke or have a highly stressful job. There is no trace of family illness. FIGURE 7 displays the model simulation for Person_Y. 
- THE REAL AGE-ADJUSTED LIFE EXPECTANCY FOR PERSON_Y IS 72 YEARS.

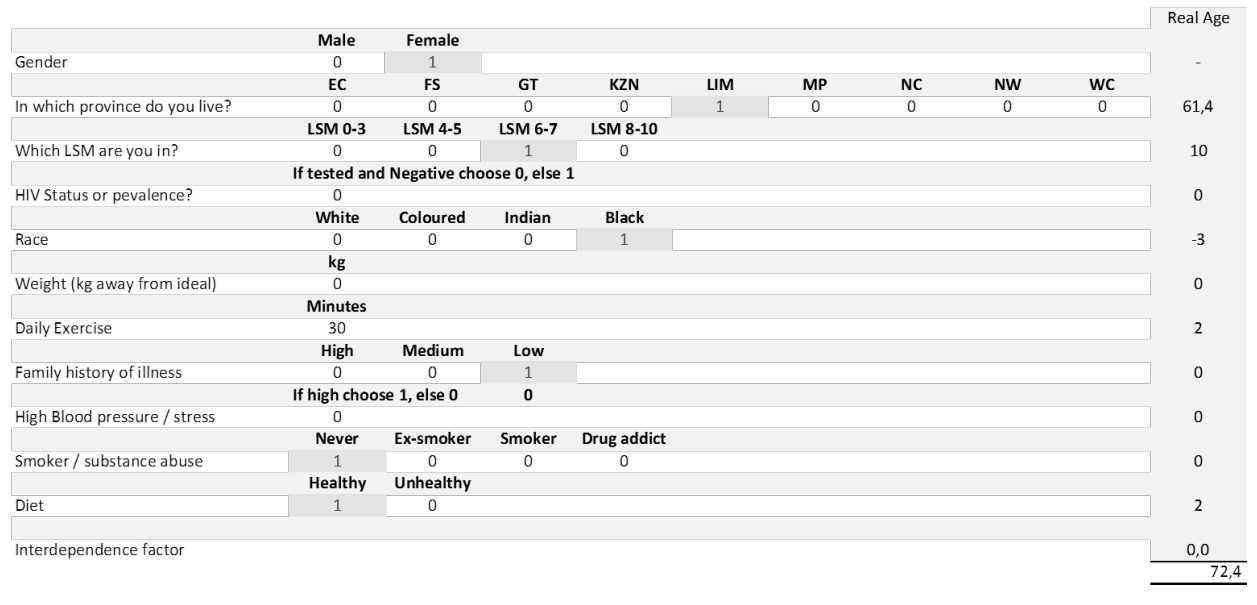

FIGURE 7: Graphical interface showing simulation of Person_y

\section{Source: Created by authors}

\subsection{Person_Z}

Person_Z is an Indian male living in Johannesburg. A self-made successful businessman, he has few financial worries, but high stress is a factor. He exercises infrequently, doesn't eat particularly healthily, and is $5 \mathrm{~kg}$ overweight as a result. His HIV test returned negative. Smoking is a family trait, though he quit a number of years ago. There are no traces of family illness. FIGURE 8 displays the model simulation for Person_Z.

- THE REAL AGE-ADJUSTED LIFE EXPECTANCY FOR PERSON_Z IS 67 YEARS

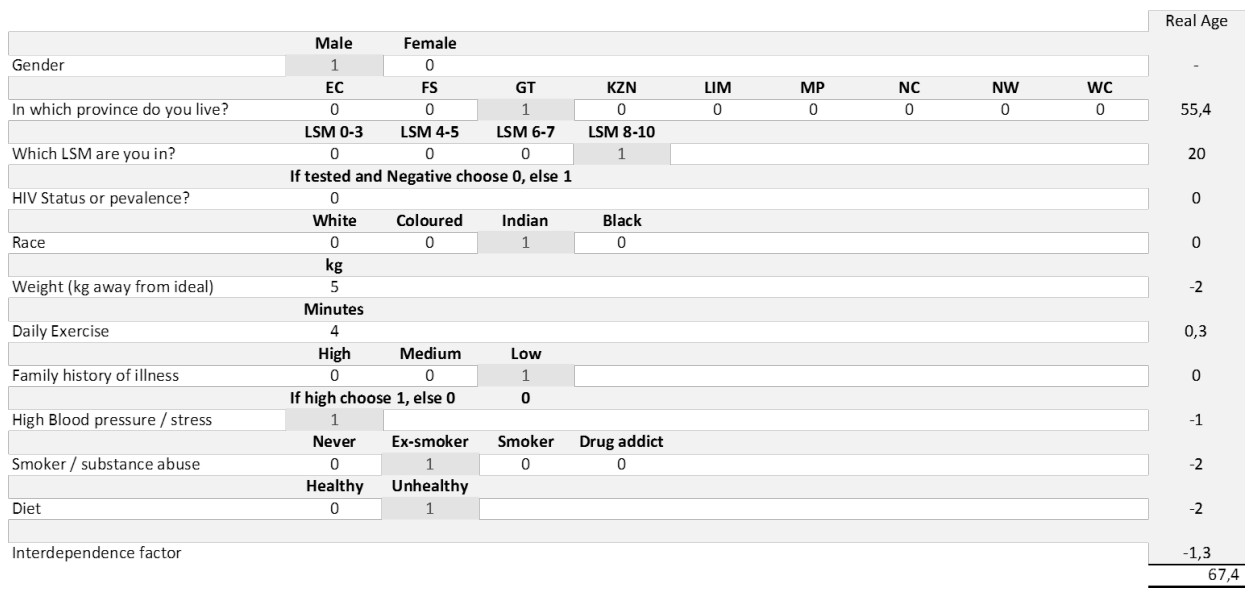

FIGURE 8: Graphical interface showing simulation of Person_Z

Source: Created by authors 


\section{CONCLUSION}

A model was built to predict an individual's Real Age-adjusted life expectancy. Eleven inputs were used, with gender, financial well-being and residing province having the largest influence on one's life expectancy. Life expectancy for three fictitious people was simulated in the Adjusted Life Expectancy Model. The results were 87,72 and 67 years. This is a noticeable change from the average 50 -year life expectancy for South Africans in general.

Results from the model form an invaluable part in retirement planning, because retirement duration determines the asset classes and corresponding weights in which the retirement funds should be invested. The person with the longest life expectancy, 87 years in the case of this study, may have to invest in a higher risk portfolio to ensure that sufficient funds are available until date of death. Conversely, it would be dangerous to base retirement planning solely on the results from the model in the case of the person with a life expectancy of 67 years. In this case he/she should err on the conservative side by assuming a significantly longer period after retirement.

The consequences of the ALE Model for retirement planning are investigated further in the article entitled "The Financial Survival Probability of Living Annuitants".

\section{LIST OF REFERENCES}

Ardington, દ. \& Lund, F. (1994). Pensions and Development: The Social Security System as a Complementary track to Programmes of Reconstruction and Development. Centre for Social and Development Studies. University of Natal.

Bankrate Life Expectancy Calculator. (2012). [0n-line] Available: http://www.bankrate.com/ calculators/retirement/life-age-expectancy-calculator.aspx. (Accessed 19 September 2012).

Barbone, L. \& Sanchez, L.A. (1999). Pensions and Social Security in Sub-Saharan Africa: Issues and options. The World Bank, Africa Region. (Working paper series no. 4).

Cutler, D.M., Fryer Jr., R.G. \& Glaeser, E.L. (2005). Racial Differences in Life Expectancy: The Impact of Salt, Slavery, and Selection. Harvard University. 1 March.

DiLorenzo, T.M., Bargman, E.P., Stucky-Ropp, R., Brassington, G.S., Frensch, P.A. \& LaFontaine, T. (1999). Long-Term Effects of Aerobic Exercise on Psychological Outcomes. Preventive Medicine, 28, pp. 75-85.

Ferrucci, L., Izmirlian, G., Leveille, S., Phillips, C.L., Corti, M., Brock, D.B. \& Guralink, J.M. (1999).

Smoking, Physical Activity, and Active Life Expectancy. American Journal of Epidemiology, 49(7), pp. 645-653.

Foster, D.P., Chua C.Z. and Ungar, L.H. (2012) How Long Will you Live? [0n-line] Available: http://gosset.wharton.upenn.edu/mortality/. (Accessed 19 September 2012).

Hughes, J.R. (1984). Psychological Effects of Habitual Aerobic Exercise: A Critical Review. Preventative Medicine, 13, pp. 66-78.

Hughes, J.R., Casal, D.C. \& Leon, A.S. (1986). Psychological Effects Of Exercise: A Randomized CrossOver Trial. Journal of Psychosomatic Research, 30(3), pp. 355-360. 
Human Sciences Research Council. (2005). National HIV prevalence in South Africa. [On-line] Available: http://www.hsrc.ac.za/Factsheet-40.phtml. (Accessed 28 December 2011).

Mail and Guardian. (2009). SA Life Expectancy Decreases. [On-line] Available: http://mg.co.za/article/2009-11-19-sa-life-expectancy-decreases. (Accessed 28 December 2011).

Mothers and Fathers. (2001). Mothers and Fathers of the Nation: The forgotten people? Ministerial Committee on Abuse, Neglect and III-Treatment of Older Persons. [0n-line] Available: http://www.saopf.org.za/policies/CONTENTS\%20Volume\%200ne\%20Page\% 20Re.pdf. (Accessed 29 December 2011).

National Health Service. (2011). HIV Patients'Life Expectancy Rises. [0n-line]. Available: http://www.nhs.uk/news/2011/100ctober/Pages/life-expectancy-uk-people-with-hivimproves.aspx. (Accessed: 5 June 2012).

National Treasury. (2004). Retirement Fund Reform, a discussion paper.

Peeters, A., Barendregt, J.J., Willekens, F., Mackenbach, J.P., Al Mamun, A. \& Bonneux, L. (2003). Obesity in Adulthood and Its Consequences for Life Expectancy: A Life-Table Analysis. American Society of Internal Medicine. 138, pp. 24-32.

South African Retirement Annuity Fund. (2011). [On-line] Available: http://www.oldmutual.co.za/personal/retirement-planning/retirement-funding/sa-retirementannuity-fund.aspx. (Accessed 30 December 2011).

Statistics South Africa. (201la). Mid-year population estimates. [0n-line] Available: http://www.statssa.gov.za/publications/P0302/P03022011.pdf. (Accessed 1 June 2012)

Statistics South Africa. (2011b). Puarterly Labour Force Survey. [0n-line] Available: http://www.statssa.gov.za/publications/P0211/P02113rdQuarter2011.pdf. (Accessed 29 December 2011).

Statistics South Africa. (2007). Community Survey, 2007. [0n-line] Available: http://www.statssa .gov.za/publications/P0301/P0301.pdf. (Accessed 30 December 2011).

Thompson, L. (2008). Best Doctors - The Celebrity. [0n-line] Available: http://www.clevelandmagazine.com. (Accessed 21 April 2012).

Tracey, T. (2012). South African Audience Research Foundation's AMPS database.

Van der Merwe, M.T. \& Pepper, M.S. (2005). Obesity in South Africa. International Association for the Study Obesity, 7, pp. 315-322.

Wen, C.P., Wai, J.P.M., Tsai, M.K., Yang, Y.C., Cheng, T.Y.D., Lee, M., Chan, H.T., Tsao, C.K., Tsai, S.P. \& Wu, X. (2011). Minimum Amount Of Physical Activity For Reduced Mortality And Extended Life Expectancy: A Prospective Cohort Study. The Lacent, 378(9798), pp. 1244-1253.

World Bank. (2011). World Development Indicators. [On-line] Available: http://data. worldbank.org/data-catalog/world-development-indicators?cid=GPD_WDI. (Accessed 28 December 2011).

World Health Organization. (2011). Obesity and Overweight. [0n-line]. Available: http://www.who.int/mediacentre/factsheets/fs311/en/index.html. (Accessed 28 December 2011). 